\title{
A Survey of Evidence for Test-Driven Development in Academia
}

\author{
Chetan Desai, David Janzen, Kyle Savage \\ Computer Science \\ California Polytechnic State University \\ San Luis Obispo, California USA \\ \{cdesai, djanzen\}@calpoly.edu \\ savage@alumni.calpoly.edu
}

\begin{abstract}
University professors traditionally struggle to incorporate software testing into their course curriculum. Worries include double-grading for correctness of both source and test code and finding time to teach testing as a topic. Test-driven development (TDD) has been suggested as a possible solution to improve student software testing skills and to realize the benefits of testing. According to most existing studies, TDD improves software quality and student productivity. This paper surveys the current state of TDD experiments conducted exclusively at universities. Similar surveys compare experiments in both the classroom and industry, but none have focused strictly on academia.
\end{abstract}

\section{INTRODUCTION}

The idea of test-driven development (TDD) has been around since the early 1960's with NASA's Project Mercury[15]. TDD received its current name and popularity after being introduced as a practice in eXtreme Programming (XP), created by Kent Beck and Ward Cunningham. XP takes twelve important fundamental software engineering practices and does them to the extreme. Testing is a fundamental practice, and XP took it to the extreme by iteratively developing tests in tandem with writing code.

\subsection{The TDD Process}

TDD develops tests and code in a unique order. TDD procedures work with units of program functionality. Units are the smallest module of functionality and are usually in the form of methods. The sequence of TDD is [3]:

1. Add a new test for an unimplemented unit of functionality.

2. Run all previously written tests and see the newly added test fail.

3. Write code that implements the new functionality.

4. Run all tests and see them succeed.

5. Refactor (rewrite to improve readability or structure).

6. Start at the beginning (repeat).

As development continues, the programmer creates a suite of unit tests that can be run automatically. As larger modules (entire classes or packages, as opposed to single methods) are completed, more tests may be added. The programmers now have a full regression test suite to run whenever changes are made to the system. Design changes can be made with confidence, since if something breaks in another part of the system, the regression tests are likely to catch it.

\subsection{Common Misconceptions}

There are many misconceptions about test-driven development. First, TDD is not a testing technique, it is a process. A popular misconception is that people think all the testing is done before any code is produced. This is wrong; units of test and code are interleaved during the development process. Ambler summarizes several misconceptions in the following list[1]:

- You create a $100 \%$ regression test suite: It is not always cost-effective to achieve $100 \%$ test coverage with all code (e.g. user interfaces).

- Unit tests form $100 \%$ of your design specification: Some design documentation is usually valuable and necessary even with TDD.

- You only need to unit test: A quality product also requires acceptance, performance, system integration and other testing techniques.

- TDD does not scale: Large test suites can be divided in order to achieve reasonable test execution times. 


\section{CURRENT STATE OF THE ART}

Table 1 summarizes most of the studies on TDD in academia. However, side by side comparisons have inherent difficulties. Many of the studies have different independent and dependent variables, with the common purpose of finding the effects of one or more aspects of TDD. Each result should be understood within the context and environment of the study. For example, controlled experiments have different control group characteristics. In cases where the control group used iterative test-last (write a unit of code, write a unit test, repeat), many quality results did not differ as much, since continuous testing was still occurring. In cases where the control group applied a traditional test-last approach (write all the code then write all the tests) or conducted no programmatic testing at all, defect counts varied significantly. Furthermore, techniques for measuring quality and productivity differed from study to study. The most common way to measure quality was the number of unit tests passed during acceptance tests. To measure productivity, many experiments had students log the time they worked, or they counted non-commented lines of code. Student confidence levels and preferences were measured through pre- and post-experiment surveys.

\subsection{TDD Benefits}

By writing tests before code, programmers are forced to 'differentiate between the functionality to implement and the base condition under which the implementation has to work'[19]. This forces programmers to make better design decisions during development. Most controlled experiments between TDD and other testing practices show an increase in quality of code, or minimal differences. Depending on what control group the TDD group was being compared against, results were between a 35\%[22] and $45 \%[5]$ reduction in defects. Changes in productivity varied by experiment. Some experiments found vast improvements in productivity, between 24.5\%[22] and $50 \%[13]$. Others found less hopeful results of a $5-10 \%$ decrease in productivity [11]. Surveys from students have indicated an increase in program understanding [18] and confidence in making changes to the code and code correctness [19]. These results tended to be more positive in more advanced courses. Mature programmers noticed the benefits of TDD and could conduct its practices correctly, where beginner programmers struggled to understand the purpose of testing.

\subsection{TDD Worries}

Adopting TDD practices in a university environment comes with several concerns. Edwards outlines five perceived roadblocks [5]:

1. Introductory students are not ready for testing until they have basic programming skills.
2. Instructors do not have enough lecture hours to teach a new topic like software testing.

3. Course staff already has its hands full grading code correctness, so it may not be feasible to assess test cases too.

4. To learn the benefits of TDD, students need frequent, concrete feedback on how to improve as they are working.

5. Students must see the value in the non-functional code (test code).

JUnit has proven to be a tough barrier in introductory programming courses. When students are learning an entirely new language like Java, trying to understand the concepts and structure of JUnit is difficult. Keefe recommends to first teach testing with sample test data, expected results, simple test plans, and retrieving actual results, before moving into TDD [14].

\subsection{Popular Frameworks}

All of the examined experiments in Table 1 used Java except one, which used Pascal [2]. By far, the most widely used language for TDD is Java, along with JUnit, its popular test harness. JUnit was developed by the inventor and advocate of TDD, Kent Beck, along with Erich Gamma. However, TDD is not limited to Java and JUnit, as there are other frameworks under the name of xUnit, used for various programming languages. JUnit was popularized by providing assertions for expected results, test fixtures for prepping and cleaning up data to perform one or more tests, and test runners to orchestrate execution of tests and report results. These abilities allow users to smoothly interchange between developing tests and code.

\subsection{TDD at Different Experience Levels}

A current pedagogical concern of professors is deciding when to introduce TDD into their curriculum. Experiments have been conducted at all student levels. Studies tend to show that beginner programmers have a hard time using TDD, especially when trying to incorporate frameworks like JUnit. For students starting to learn what programming is and how it works, they find it tough to find purpose in the code, so testing it is difficult [14]. Tools like WebCAT [4] and Marmoset [21] have helped overcome testing hurdles. By providing feedback such as test coverage and number of unit tests passed, writing tests becomes meaningful to a programming novice. This helps to eliminate the need for counterproductive practices, such as forcing beginners to write tests as a part of their grade. Students writing tests in this manner does not prove they are doing it because of the benefit they get out of testing; they may simply be writing the tests as an afterthought since their grade depends on it. When left to the students to decide to write tests or not, only $10 \%$ wrote tests [2]. 
Table 1: Comparison Grid

\begin{tabular}{|c|c|c|c|c|c|c|}
\hline Study & Type & Student Level & Subjects & $\begin{array}{l}\text { Productivity of } \\
\text { Students }\end{array}$ & $\begin{array}{l}\text { Quality of } \\
\text { Programs }\end{array}$ & Other Findings \\
\hline Muller [19] & Case Study & Graduate & 11 & & & $\begin{array}{c}87 \% \text { stated regression testing } \\
\text { increased confidence }\end{array}$ \\
\hline Edwards [5] & Cont. Exp. & Junior & $\begin{array}{c}118 \text { (59 TDD / } 59 \\
\text { Control) }\end{array}$ & & $45 \%$ fewer defects & Increased student confidence \\
\hline Erdogmus [6] & Cont. Exp. & Junior & $\begin{array}{l}24 \text { (11 TDD / } 13 \\
\text { Control) }\end{array}$ & $52 \%$ increase & No effect & $\begin{array}{c}\text { Minimum quality increased } \\
\text { linearly with number of } \\
\text { tests. }\end{array}$ \\
\hline Janzen [8] & Cont. Exp. & Freshman & $\begin{array}{c}27 \text { (13 TDL / } 14 \text { non- } \\
\text { TDL) }\end{array}$ & & & $\begin{array}{c}\text { TDL students had slightly } \\
\text { better comprehension, } \\
\text { scoring } \sim 10 \% \text { higher on a } \\
\text { quiz. }\end{array}$ \\
\hline Janzen $[10]$ & Cont. Exp. & Freshman & $\begin{array}{c}\text { CS1: } 106 \text { ( } 40 \text { TDD, } \\
\text { 66 Control) } \\
\text { CS2: } 36 \text { (6 TDD, } 30 \\
\text { Control) }\end{array}$ & $\begin{array}{l}\text { CS1: Slower but } \\
\text { not stat. sig. } \\
\text { CS2: Faster but } \\
\text { not stat. sig. }\end{array}$ & $\begin{array}{l}\text { CS1: TDD } \\
\text { Students wrote } \\
\text { more asserts. } \\
\text { CS2: TDD } \\
\text { projects superior } \\
\text { to control group. }\end{array}$ & $\begin{array}{l}\text { TDD students felt more } \\
\text { confident in their code w.r.t. } \\
\text { quality, change, and reuse. }\end{array}$ \\
\hline Kaufmann [13] & Cont. Exp. & $\begin{array}{l}\text { Sophomore - } \\
\text { Senior }\end{array}$ & 4 (2 TDD / 2 Control) & $\begin{array}{l}50 \% \text { more } \\
\text { NLOC }\end{array}$ & $\begin{array}{l}\text { Better CCCC } \\
\text { metrics }\end{array}$ & $\begin{array}{l}\text { Increased student } \\
\text { confidence. }\end{array}$ \\
\hline Madeyski [16] & Cont. Exp. & Graduate & 188 & & $\begin{array}{l}\text { External code } \\
\text { quality stat. sig. } \\
\text { lower }\end{array}$ & \\
\hline Muller [18] & Cont. Exp. & Graduate & $\begin{array}{c}19 \text { (10 TDD / } 9 \\
\text { Control })\end{array}$ & $\begin{array}{l}\text { Faster but not } \\
\text { stat. sig. }\end{array}$ & $\begin{array}{c}\text { Less reliable w.r.t. } \\
\text { passed assertion } \\
\text { tests but not stat. } \\
\text { sig. }\end{array}$ & $\begin{array}{l}\text { Better program } \\
\text { understanding w.r.t. code } \\
\text { reuse. }\end{array}$ \\
\hline Pancur [20] & Cont. Exp. & Senior & $\begin{array}{c}34 \text { (19 TDD / } 15 \\
\text { Control) }\end{array}$ & $2.5 \%$ slower & & $\begin{array}{l}90 \% \text { students would accept } \\
\text { TDD in industry. }\end{array}$ \\
\hline Yenduri [22] & Cont. Exp. & Senior & $\begin{array}{c}18 \text { (9 TDD / } 9 \\
\text { Control) }\end{array}$ & $25.4 \%$ faster & $\begin{array}{l}34.8 \% \text { fewer } \\
\text { defects }\end{array}$ & \\
\hline Barriocanal [2] & Exp. Report & Freshman & 100 & & & $\begin{array}{c}\text { Only } 10 \% \text { students wrote } \\
\text { test cases by choice }\end{array}$ \\
\hline Keefe [14] & Exp. Report & Freshman & 12 & & & $\begin{array}{l}\text { Of XP practices, TDD not } \\
\text { preferred. }\end{array}$ \\
\hline Melnik [17] & Exp. Report & $\begin{array}{l}\text { Freshman - } \\
\text { Graduate }\end{array}$ & 240 & $\begin{array}{l}78 \% \text { agreed on } \\
\text { improvement }\end{array}$ & $\begin{array}{c}76 \% \text { agreed on } \\
\text { improvement }\end{array}$ & $\begin{array}{l}\text { Correlation between age and } \\
\text { attitude towards TDD. }\end{array}$ \\
\hline Spacco $[21]$ & Exp. Report & Freshman & $20-30$ & & & $\begin{array}{l}\text { Students need incentives to } \\
\text { adopt test-first mentality } \\
\text { early. }\end{array}$ \\
\hline Janzen [9] & Field Study & $\begin{array}{l}\text { Freshman - } \\
\text { Graduate }\end{array}$ & $\begin{array}{l}160 \text { (130 beginners / } \\
30 \text { mature })\end{array}$ & & & $\begin{array}{l}87 \% \text { mature programmers } \\
\text { prefer TDD, } 86 \% \text { beginner } \\
\text { programmers prefer test-last. }\end{array}$ \\
\hline Janzen [7] & Survey & & & $\begin{array}{c}\text { Increased or no } \\
\text { effect }\end{array}$ & $\begin{array}{l}\text { Improved or no } \\
\text { effect }\end{array}$ & \\
\hline Jeffries [11] & Survey & & & $\begin{array}{c}\text { Increased efforts } \\
5-35 \%\end{array}$ & $\begin{array}{c}40-80 \% \text { drop in } \\
\text { defects }\end{array}$ & \\
\hline Jones [12] & Survey & & & $\begin{array}{c}\text { Increased or no } \\
\text { effect }\end{array}$ & $\begin{array}{c}\text { Improved or no } \\
\text { effect }\end{array}$ & $\begin{array}{l}\text { Increased program } \\
\text { understanding. }\end{array}$ \\
\hline
\end{tabular}

Legend:

NLOC: non-commented lines of code. Cont. Exp.: controlled experiment. CCCC: C and C++ Code Counter.

Exp. Report: experience report. Stat. Sig.: statistically significant. w.r.t.: with respect to TDL: test-driven learning.

Results have been much more promising at higher levels of education. Many mature programmers see the benefits of TDD such as increased productivity and quality $[17,9]$. As seen in Table 1, most of the success stories come from experiments conducted between junior undergraduate and graduate levels of education. Does this mean that TDD should not be used in introductory programming courses? No. It means that a lot more work needs to go into course plans.

\section{INTRODUCING TDD}

Determining when and how to introduce TDD practices into a curriculum can be difficult. Most of the experiments introduced TDD at the beginning of the semesters. Introductions usually consisted of: 
- Explaining automated unit testing

- Describing TDD

- Providing documentation

- Supplying examples of how to write test cases, execute test cases, and interpret results

Introduction lengths varied from a thirty-minute lecture[4] to a three-week topic[19]. Looking back on Table 1, promising results came from Edwards[5], where TDD practices were introduced briefly at the start of the semester, but then used in the classroom throughout the entire experiment to model behavior. Reinforced learning could be a key to successfully introducing TDD, but controlled experiments will have to be conducted with using TDD in the classroom to model examples as the independent variable. In cases where students were just briefly introduced to testing at the start of the semester, TDD was not preferred[14] and only $10 \%$ of the students wrote test cases[2].

\section{TEST-DRIVEN LEARNING}

With an incremental instructional approach, students would first learn programming syntax and semantics. Then, move into concepts of test data, test plans, and expected results. Once they are comfortable with that, techniques like TDD can be introduced, using tools such as JUnit, WebCAT, and Marmoset to help facilitate understanding.

In contrast to this incremental approach, test-driven learning (TDL)[8] proposes teaching by example, presenting examples with automated tests, and starting with tests. TDL was proposed in SIGCSE 06 as a pedagogical tool for incorporating automated unit testing in computer programming courses. TDL needs little to no additional instruction time and targets any level of programming student or industry professional. Although TDL is presented as a test-first approach, a test-last approach can be equally beneficial. To achieve its goal of writing good tests, TDL is designed to present testing early and use it as a recurring theme throughout a course. According to [8], objectives behind TDL include:

- Teaching testing for free

- Teaching automated testing frameworks simply

- Encouraging the use of TDD

- Improving student comprehension and programming abilities

- Improving software quality both in terms of design and defect density

A short experiment was conducted and showed that TDL could be introduced with positive feedback at no additional teaching time or student effort. A subsequent TDL experiment on a CS1 course and a CS2 course [10] found that test-first programmers wrote more tests and scored higher on project grades than their test-last counterparts when taught in a TDL fashion.

\section{CONCLUSIONS AND FUTURE STUDIES}

TDD in academia has moved on from its conception stage, and many studies have tried to prove correlations and effects. Studies show that TDD exposes students to analytical and comprehension skills needed in software testing. As a programming technique more than a testing process, TDD tends to help students with the design of complex projects, and increases student confidence. Controlled experiments can help determine when to introduce TDD in education, by using the independent variable of student class-level. Once an appropriate classlevel is determined, more experiments should be conducted which identify optimal teaching plans, feedback mechanisms, and test harnesses for that level. Test-driven development reveals valuable software testing skills to fledgling programmers; the next step is figuring out how and when to introduce it into a curriculum.

\section{REFERENCES}

[1] S. Ambler. Test-Driven Development is the Combination of Test First Development and Refactoring. Dr. Dobbs' Agile Newsletter, June 12, 2006.

[2] E. Barriocanal, M. Urban, I. Cuevas, and P. Perez. An Experience in Integrating Automated Unit Testing Practices in an Introductory Programming Course. ACM SIGCSE Bulletin, 34(4):125-128, December 2002.

[3] K. Beck. Test Driven Development: By Example. Addison Wesley, November 2002.

[4] S. Edwards. Using Test-Driven Development in the Classroom: Providing Students with Automatic, Concrete Feedback on Performance. In Proc. Intl' Conf. on Education and Information Systems: Technologies and Applications (EISTA), August 2003.

[5] S. Edwards. Using Software Testing to Move Students from Trial-and-Error to Reflection-in-Action. ACM SIGCSE Bulletin, 36(1):26-30, March 2004.

[6] H. Erdogmus, M. Morisio, and M. Torchiano. On the Effectiveness of the Test-First Approach to Programming. IEEE Trans. Software Eng., 31(3):226-237, March 2005.

[7] D. Janzen and H. Saiedian. Test-Driven Development: Concepts, Taxonomy, and Future Direction. IEEE Computer, 38(9):43-50, September 2005.

[8] D. Janzen and H. Saiedian. Test-Driven Learning: Intrinsic Integration of Testing into the CS/SE Curriculum.. In Proc. 37th Technical Symposium on Computer Science Education (SIGCSE), pages 254258. ACM, 2006.

[9] D. Janzen and H. Saiedian. A Leveled Examination of Test-Driven Development Acceptance. In Proc. 29th Intt' Conf. on Software Engineering (ICSE), pages 719722. IEEE Press, 2007.

[10] D. Janzen and H. Saiedian. Test-Driven Learning in Early Programming Courses. In Proc. 39th Technical Symposium on Computer Science Education (SIGCSE). ACM, 2008. 
[11] R. Jeffries and G. Melnik. TDD: The Art of Fearless Programming. IEEE Software, 24(3):2430, May-June 2007.

[12] C. Jones. Test-Driven Development Goes to School. Journal of Computing Sciences in Colleges, 20(1):220-231, October 2004.

[13] R. Kaufmann and D. Janzen. Implications of Test-Driven Development: A Pilot Study. In Companion of the 18th Ann. ACM SIGPLAN Conf. Object-Oriented Programming, Systems, Languages, and Applications, pages 298299. ACM Press, 2003.

[14] K. Keefe, J. Sheard, and M. Dick. Adopting XP Practices for Teaching Object Oriented Programming. In Proc. 8th Australian Conf. Computing Education, volume 52, pages 91-100, 2006.

[15] C. Larman and V. Basili. Iterative and Incremental Developments. A Brief History. IEEE Computer, 36(6):47-56, June 2003.

[16] L. Madeyski. Preliminary Analysis of the Effects of Pair Programming and Test-Driven Development on the External Code Quality. Software Engineering: Evolution and Emerging Technologies, 130:113-123, 2005.

[17] G. Melnik and F. Maurer. A Cross-Program Investigation of Students'Perceptions of Agile Methods. In Proc. 27th Int' Conf. on Software Eng. (ICSE), pages 481-488. ACM Press, 2005.

[18] M. Muller and O. Hagner. Experiment About Test-First Programming. IEEE Proc. Software, 149(5):131-136, October 2002.

[19] M. Muller and W. Tichy. Case Study: Extreme Programming in a University Environment. In Proc. 23th Int' Conf. on Software Eng. (ICSE), pages 537544, May 2001.

[20] M. Pancur, M. Ciglaric, M. Trampus, and T. Vidmar. Towards Empirical Evaluation of Test-Driven Development in a University Environment. In IEEE Region 8 Proc. EUROCON, volume 2, pages 83-86. IEEE Press, September 2003.

[21] J. Spacco and W. Pugh. Helping Students Appreciate Test-Driven Development (TDD). In Companion to 21st. ACM SIGPLAN Conf. Object-Oriented Prog. Systems, Languages, and Applications (OOPSLA), pages 907-913, 2006.

[22] S. Yenduri and L. Perkins. Impact of Using Test-Driven Development: A Case Study. Software Engineering Research and Practice, pages 126-129, 2006. 